\title{
Secretomic profiling of cells from hollow fiber bioreactor reveals PSMA3 as a potential cholangiocarcinoma biomarker
}

\author{
CHRIS VERATHAMJAMRAS ${ }^{1}$, CHURAT WEERAPHAN ${ }^{1,2}$, DARANEE CHOKCHAICHAMNANKIT ${ }^{1}$, \\ KAMOLWAN WATCHARATANYATIP ${ }^{1}$, PANTIPA SUBHASITANONT ${ }^{1}$, PENCHATR DISKUL-NA-AYUDTHAYA $^{1}$, \\ KANOKWAN MINGKWAN ${ }^{3}$, VIRAT LUEVISADPAIBUL ${ }^{4}$, SOMCHAI CHUTIPONGTANATE $^{5}$, \\ VORARATT CHAMPATTANACHAI ${ }^{1}$, JISNUSON SVASTI ${ }^{1,6}$ and CHANTRAGAN SRISOMSAP ${ }^{1}$ \\ ${ }^{1}$ Laboratory of Biochemistry, Chulabhorn Research Institute, Bangkok 10210; ${ }^{2}$ Department of Molecular Biotechnology \\ and Bioinformatics, Faculty of Science, Prince of Songkla University, Songkla 90110; ${ }^{3}$ Department of Surgery, \\ Sappasitthiprasong Hospital; ${ }^{4}$ Division of Information and Technology, Ubonrak Thonburi Hospital, \\ Ubon Ratchathani 34000; ${ }^{5}$ Pediatric Translational Research Unit, Department of Pediatrics, \\ Faculty of Medicine, Ramathibodi Hospital, Mahidol University, Bangkok 10400; \\ ${ }^{6}$ Applied Biological Sciences Program, Chulabhorn Graduate Institute, Bangkok 10210, Thailand
}

Received March 20, 2017; Accepted May 5, 2017

DOI: 10.3892/ijo.2017.4024

\begin{abstract}
Cholangiocarcinoma (CCA), derived from the bile duct, occurs with a relatively high incidence in Northeast Thailand. Early diagnosis is still hampered by the lack of sufficient biomarkers. In recent years, biomarker discovery using secretomes has provided interesting results, including our studies on CCA secretomes, especially with three-dimensional cell cultures. Thus, cells cultured using the hollow fiber bioreactor (HFB) with $20 \mathrm{kDa}$ molecular weight cut-off (MWCO) yielded higher quality and quantity of secretomes than those from conditioned media of the monolayer culture (MNC) system. In this study, we employed the HFB culture system with $5 \mathrm{kDa}$ MWCO and compared conditioned media from the HFB and MNC systems using two-dimensional gel electrophoresis, followed by identifying proteins of interest by liquid chromatography and mass spectrometry (LC/MS/MS). Two out of 4 spots of NGAL or lipocalin-2 were found to show highest increase in expression of 19.93-fold and 18.79-fold in HFB compared to MNC. Interestingly, all 14 proteasome subunits including proteasome subunit $\alpha$ type- 1 to type-7 and $\beta$ type-1 to type-7 showed 2.92-fold to 12.13-fold increased expression in HFB. The protein-protein interactions of upregulated proteins were predicted, and one of the main interaction clusters involved $20 \mathrm{~S}$ proteasome subunits. Proteasome activity in the HFB conditioned media was also found to be
\end{abstract}

Correspondence to: Dr Chantragan Srisomsap, Laboratory of Biochemistry, Chulabhorn Research Institute, 54 Kamphaeng Phet 6, Talat Bang Khen, Bangkok 10210, Thailand

E-mail: chantragan@cri.or.th

Key words: biomarker, cholangiocarcinoma, hollow fiber bioreactor, proteasome, proteasome subunit $\alpha$ type-3, secretome higher than that in MNC conditioned media. Three types of proteasome subunit were also validated by immunoblotting and showed higher expression in the HFB system compared to MNC system. Proteasome subunit $\alpha$ type-3 (PSMA3) showed the highest level in plasma of cholangiocarcinoma patients compared to normal and hepatocellular carcinoma patients by immunodetection, and is of interest as a potential biomarker for cholangiocarcinoma.

\section{Introduction}

Cholangiocarcinoma (CCA), an aggressive malignancy, is derived from the epithelial cells of bile duct. It is a relatively rare cancer associated with poor outcomes; however, its incidence and mortality rates are progressively increasing worldwide (1). CCA occurs with a relatively high incidence in the Northeast Thailand and is often associated with liver fluke (Opisthorchis viverrini) infestation and nitrosamine intake (2). Early diagnosis is still difficult due to lack of the specific biomarkers. Thus far, serum biomarkers of CCA include carbohydrate antigen 19-9 (CA19-9) and carcinoembryonic agent (CEA), but these proteins are also present in other diseases like cholangitis and pancreatitis $(3,4)$. Novel biomarkers for CCA have been investigated, including matrix metalloproteinase-7 (5), miRNAs (6), interleukin-6 (7), and sperm-specific protein 411 (SSP411) (8) but none have been used with the patients yet.

Biomarker discovery using secretomes, containing the secreted macromolecules from cells, has yielded interesting results (9). Our previous study on the secretomes of cholangiocarcinoma cells in comparison to 4 other hepatocellular carcinoma cells revealed that lipocalin-2 (NGAL) and 49 other proteins were present only in the secretion of the cholangiocarcinoma cell, and NGAL was proposed to be a potential biomarker (10). Three-dimensional (3D) cell culture is now receiving more interest, since it mimics the in vivo condition. Our group reported the use of scaffold-based 
3D culture and hollow fiber bioreactor (HFB), a 3D culture system based on hollow fiber cartridges, for preparing secretomes $(11,12)$. Comparison of the secretome proteins from a $3 \mathrm{D}$ culture system with those from conditioned media of monolayer culture (MNC) system indicated effective enrichment of secretomes from the HFB system compared to those from MNC in terms of both quality and quantity (12). At that time, using a cartridge with a $20 \mathrm{kDa}$ molecular weight cut-off (MWCO), C19orf10 and cystatin B proteins were found to be present only in the HFB system, and the expression level of 75 protein spots was significantly increased compared to the MNC system.

The 20S proteasome is a proteolytic core of the proteasome complex, which is involved in the degradation of misfolded and damaged proteins. It is a barrel-like structure in which the 28 subunits are assembled into four stacked heptametrical ring: two outer rings composed of seven $\alpha$-subunits $(\alpha 1-\alpha 7)$ and two inner rings composed of seven $\beta$-subunits ( $\beta 1-\beta 7)(13)$. Accumulating evidence suggests that proteasome activity is elevated in various types of cancer cells (14-16). This agrees with the fact that cancer cells are more sensitive to proteasome inhibitor than normal cells. Of note, the $20 \mathrm{~S}$ proteasome is also detectable in human plasma and designated as a circulating proteasome (17). Interestingly, the concentration of circulating proteasome has been reported to be increased and associated with the stage of cancer (18).

In this report, the HFB system with a $5 \mathrm{kDa} \mathrm{MWCO}$ was studied. With this $5 \mathrm{kDa}$ MWCO cartridge, most secreted proteins were retained and harvested for proteomic analysis. The secreted proteins from conditioned media of HFB and MNC systems were compared by two-dimensional gel electrophoresis (2DE) and identified by liquid chromatography mass spectrometry (LC/MS/MS). The different expression levels of interesting proteins were quantitatively-analyzed and confirmed by immune detection. Moreover, a candidate protein, proteasome subunit $\alpha$ type-3 (PSMA3), was validated in plasma samples from normal, liver cancer and cholangiocarcinoma patients.

\section{Materials and methods}

Plasma collection. Specimens were collected at Sappasitthiprasong Hospital, Ubon Ratchathani, Thailand. The definitive diagnosis of cholangiocarcinoma and hepatocellular carcinoma was based on the histopathological examination of biopsy or surgical specimens. Detailed information of patients ( $n=7 ; 4$ cholangiocarcinoma and 3 hepatocellular carcinoma) including sex, age, the definitive diagnosis and staging are shown in Table I. Blood specimens were collected at the first patient visit when there was clinical suspicion of cholangiocarcinoma, because of signs and symptoms of obstructive jaundice and presence in a population at risk in the high prevalence area. Control blood group $(n=5 ; 3$ males, 2 females, with average age of 53.8 \pm 2.7 ) was defined as healthy individuals who presented for an annual checkup. Plasma-EDTA samples were retrieved as left-over specimens within 30 min after routine complete blood counting and then kept aliquots at $-80^{\circ} \mathrm{C}$ until used. The study was approved by the local ethics committee of Faculty of Medicine Ramathibodi Hospital, Mahidol University and Sappasitthiprasong Hospital (Protocol
ID 03-58-68) and written informed consent was waived due to use of left-over specimens.

Monolayer culture system. Human cholangiocarcinoma cell line (HuCCA-1) originating from a Thai patient (19) was cultured in Ham's F-12 (Gibco; Thermo Fisher Scientific, Inc., Waltham, MA, USA) with $10 \%$ fetal bovine serum (FBS, Hyclone; GE Healthcare Life Sciences, Chicago, IL, USA) and $1 \%$ antibiotic-antimycotic (Gibco). Hepatocellular carcinoma cell line (HCC-S102) established from a Thai patient (20) was grown in RPMI-1640 (Gibco; Thermo Fisher Scientific, Inc.) containing $10 \%$ FBS (Hyclone) and $1 \%$ antibiotic-antimycotic. After the cells reached $\sim 70 \%$ confluence, culture medium was replaced with serum-free medium. The culture was further incubated for $24 \mathrm{~h}$ before the entire conditioned medium was harvested. For experiments comparing MNC and HFB systems, HuCCA-1 cells were cultured in the serum-free media with a CDM-HD serum replacement (FiberCell ${ }^{\circledR}$ Systems Inc., Frederick, MD, USA) as described in our previous study (12). The conditioned media were collected daily and replaced with fresh media. The collected media were harvested by sequential centrifugation at $480 \mathrm{xg}$ at $4^{\circ} \mathrm{C}$ for $5 \mathrm{~min}$ and 2,000 $\mathrm{x}$ g for $10 \mathrm{~min}$ to remove contaminated cells and cell debris, respectively. After centrifugation, the conditioned media were kept at $-80^{\circ} \mathrm{C}$ until use.

Hollow fiber bioreactor culture system. Approximately $1 \times 10^{8}$ CDM-adapted HuCCA-1 cells were inoculated into the hollow fiber bioreactor with a $5 \mathrm{kDa}$ MWCO cartridge (\#C2008, FiberCell Systems Inc.) according to the manufacturer's instructions. The entire conditioned media were collected daily and the fresh new media were replaced. The collected media were harvested using the same protocol performed in the MNC system as described previously.

Measurement of glucose consumption. The growth of cells cultured in the HFB and MNC systems was indirectly monitored by glucose consumption. The depletion rate of glucose in the media was determined using a blood glucose meter (Medisafe-mini GR-102, Terumo Co., Tokyo, Japan) as previously described (12).

Measurement of lactate dehydrogenase release. The lactate dehydrogenase (LDH) cytotoxicity detection kit (Takara Bio USA, Inc., Mountain View, CA, USA) was used to determine the extent of cell leakage. Briefly, $100 \mu \mathrm{l}$ of conditioned media was mixed with an equal volume of the assay mixture (catalyst, dye, and reaction mixture). The reaction mixtures were incubated at room temperature for $30 \mathrm{~min}$ in the dark and stopped by adding 1/10 volume of $1 \mathrm{~N} \mathrm{HCl}$. End product was measured by a microplate reader (Molecular Devices, LLC., Sunnyvale, CA, USA) with the absorbance at 450 and $690 \mathrm{~nm}$.

Two-dimensional gel electrophoresis and image analysis. The conditioned media were concentrated by an Amicon ${ }^{\circledR}$ Ultra Centrifugal Filter Unit with 3 kDa MWCO (Merck KGaA, Darmstadt, Germany). Then trace contaminants were removed using a 2-D Clean-Up kit (GE Healthcare Life Sciences). The sample was then resuspended in $2 \mathrm{D}$ lysis buffer containing $7 \mathrm{M}$ 
Table I. Detailed characteristics of patients.

\begin{tabular}{lcccc}
\hline Sample ID & Male/Female & Age & Diagnosis & Staging \\
\hline C1 & M & 55 & Cholangiocarcinoma, intrahepatic & $4 \mathrm{~A}$ \\
C2 & $\mathrm{M}$ & 67 & Cholangiocarcinoma, intrahepatic & 3 \\
C3 & $\mathrm{F}$ & 55 & Cholangiocarcinoma, intrahepatic & 3 \\
C4 & $\mathrm{M}$ & 46 & Cholangiocarcinoma, perihilar & 1 \\
C5 & $\mathrm{F}$ & 72 & Hepatocellular carcinoma with chronic cholangitis & $3 \mathrm{C}$ \\
C6 & $\mathrm{M}$ & 52 & Hepatocellular carcinoma with cirrhosis & $3 \mathrm{~A}$ \\
C7 & $\mathrm{F}$ & 61 & Hepatocellular carcinoma & 1 \\
\hline
\end{tabular}

urea, $2 \mathrm{M}$ thiourea, $130 \mathrm{mM}$ DTT, 4\% CHAPS, 2\% ampholine $\mathrm{pH}$ 3.0-10.0 Iso-Dalt (Servalyt), $30 \mu \mathrm{M}$ Tris buffer, and cOmplete $^{\mathrm{TM}}$ Mini protease inhibitor cocktail (Roche Molecular Systems, Inc., Pleasanton, CA, USA) and incubated at room temperature for $30 \mathrm{~min}$. The protein concentration was determined using Bio-Rad protein assay (Bio-Rad Laboratories, Hercules, CA, USA). Protein samples $(100 \mu \mathrm{g})$ were adjusted to $50 \mu \mathrm{l}$ with 2D lysis buffer and mixed with $75 \mu \mathrm{l}$ of rehydration buffer containing $8 \mathrm{M}$ urea, $18 \mathrm{mM}$ DTT, 2\% CHAPS, and 2\% IPG buffer $\mathrm{pH}$ 3.0-10.0 NL (GE Healthcare Life Sciences). The sample was left at room temperature for another $30 \mathrm{~min}$ before applied to IPG strips, $7 \mathrm{~cm}$, pH 3.0-10.0 non-linear (GE Healthcare Life Sciences) for $16 \mathrm{~h}$. The first dimension separation was performed at $20^{\circ} \mathrm{C}$ with $50 \mu \mathrm{A}$ per strip with Ettan IPGphor 3 (GE Healthcare Life Sciences) according to the manufacturer's instructions. The IPG strip was equilibrated and separated by $12.5 \%$ SDS polyacrylamide gel electrophoresis (SDS-PAGE) using a SE600 Ruby apparatus (GE Healthcare Life Sciences) at a current of $25 \mathrm{~mA}$ per gel, as previously described (21). The gel was stained using Sypro ${ }^{\circledR}$ Ruby (Molecular Probes; Thermo Fisher Scientific, Inc.) and scanned using an Ettan DIGE Imager (GE Healthcare Life Sciences). The gel image was analyzed by ImageMaster 2D Platinum 7.0 software (GE Healthcare Life Sciences).

Protein identification by mass spectrometry. The protein spots were excised and subjected for in-gel digestion as described (10). The digested peptides were identified by a nanoflow liquid chromatography system using a C18 Easy-nLC ${ }^{\text {TM }}$ (75 $\mu \mathrm{m}$ id $\mathrm{x} 100 \mathrm{~mm}$ ) column (Thermo Fisher Scientific, Inc.) coupled with the amaZon speed ion trap mass spectrometer (Bruker, Billerica, MA, USA). Protein identification was interpreted using a MASCOT search engine (www.matrixscience. com) with the SwissProt database, limited to Homo sapiens only, with default settings except for the following parameters: $0.3 \mathrm{Da}$ for peptide tolerance and MS/MS tolerance; $1+, 2+$, and $3+$ for peptide charge; and ESI-TRAP for Instrument.

Bioinformatics analysis. The STRING software version 9.1 (http://string-db.org/) was used to predict the potential proteinprotein interactions and the clusters of the function were grouped. The proteins with 2-fold higher expression in HFB in comparison to MNC with statistical difference $(\mathrm{p}<0.05)$ were selected.
Validation of proteins by western blotting. Protein samples $(15 \mu \mathrm{g})$ were separated by $12.5 \%$ SDS-PAGE and transferred onto Immobilon-P membrane (Millipore, Merck KGaA). The membrane was blocked with $0.1 \%$ Tween-20 in Tris-buffer saline (TBS/T) containing 5\% BSA for $1 \mathrm{~h}$ at room temperature, followed by probing overnight at $4^{\circ} \mathrm{C}$ with monoclonal antibodies against human neutrophil gelatinase-associated lipocalin (NGAL) (1:200, Abcam Cambridge, UK), L-plastin (LCP1) (1:400, Abcam), protein deglycase DJ-1 (DJ-1) (1:2,000, Abcam), $\alpha$-enolase (ENO1) (1:2,000, Abcam), topoisomerase (TPI) (1:4,000, Abcam), proteasome subunit $\alpha$ type-3 (PSMA3) (1:5,000, Cell Signaling Technology, Inc., Danvers, MA, USA), proteasome subunit $\alpha$ type-6 (PSMA6) (1:5,000, Abcam), and proteasome subunit $\beta$ type-6 (PSMB6) $(1: 2,000$, Abcam). The membrane was incubated with the corresponding secondary antibodies (Dako; Agilent Technologies, Santa Clara, CA, USA). Protein signal was detected by a WesternBright ECL (Advansta, Inc., Menlo Park, CA, USA) using an ImageQuant LAS 4000 mini digital imaging system (GE Healthcare Life Sciences).

Depletion of high abundance plasma proteins and western blot analysis. High abundance proteins were removed from human plasma samples using the Pierce ${ }^{\mathrm{TM}}$ Top 2 Abundant Protein Depletion Spin Columns (Thermo Fisher Scientific, Inc.) according to the manufacturer's instructions. Briefly, $10 \mu \mathrm{l}$ of each sample was applied to the column and rotated gently end over end at room temperature for $30 \mathrm{~min}$. The columns were spun down at 1,000 $\mathrm{xg}$ for $2 \mathrm{~min}$. The depleted samples were collected and then concentrated using an Amicon Ultra0.5 Centrifugal Filter, with 3 kDa MWCO (Merck KGaA). Samples were centrifuged at $14,000 \mathrm{x}$ g for $60 \mathrm{~min}$ at $4^{\circ} \mathrm{C}$ and the filtrate was discarded. The filter devices were then placed upside down in a new tube and spun down at 1,000 $\mathrm{x} g$ for 2 min in order to collect the remaining concentrated sample. Total protein concentrations of samples were determined by Bradford protein assay (Bio-Rad Laboratories). Protein samples $(20 \mu \mathrm{g})$ were separated and immunoblotted with an antibody against PSMA3as described above.

Proteasome activity assay. Secreted proteins from each condition were buffer-exchanged into $1 \mathrm{X}$ PBS using Bio-Spin 6 columns (Bio-Rad Laboratories), followed by determination of proteasomal activity using a Proteasome Activity Fluorometric 
assay kit (BioVision, Inc., Milpitas, CA, USA) according to the manufacturer's instructions. Briefly, $10 \mu \mathrm{g}$ of each sample was adjusted to $50 \mu 1$ with PBS, mixed with $50 \mu 1$ of assay buffer, $1 \mu \mathrm{l}$ of substrate, and $1 \mu \mathrm{l}$ of inhibitor or assay buffer. The reaction was monitored every $10 \mathrm{~min}$ using a fluorescentmicroplate reader with the excitation at $350 \mathrm{~nm}$ and the emission at $440 \mathrm{~nm}$. The specific activity of proteasome was then calculated as the difference of relative fluorescence units divided time per micrograms of protein used.

Statistical analysis. The difference between mean values between groups was analyzed by using one-way ANOVA with post hoc Tukey HSD analysis. Values were considered statistically significant at $\mathrm{p}<0.05$.

\section{Results}

Cell viability in $H F B$ and $M N C$. Since the viability of cells cultured in HFB could not be directly determined, the glucose consumption and the cellular release of lactate dehydrogenase were measured to observe the cell growth and cellular cytotoxicity, respectively. Glucose consumption of the cells grown in HFB was increased until the end of the observation period at day 9 , while cell leakage as detected by lactate dehydrogenase release showed a slight decrease with the observation period (Fig. 1A). On the other hand, the glucose consumption of the cells cultured in MNC increased continuously until day 4 before entering into a stationary phase on day 5 and 6 and then decreasing afterwards, while the lactate dehydrogenase release was stable during the first 4 days and increased from day 5 onwards (Fig. 1B). These results suggested that the cells cultured in HFB were in good condition and kept growing throughout the experiment, while the growth of cells in MNC was limited to the first 5 days. Therefore, the conditioned media were collected at day 4 for each experiment for further analysis.

Comparison of the expression of CCA secretomes between $H F B$ and MNC systems. The conditioned media of cholangiocarcinoma cells from HFB and MNC systems were collected separately and analyzed using 2DE (Fig. 2). The ImageMaster software version 7.0 was employed to analyze the protein spots. The results showed that 1,003 spots were detected in HFB, while 977 spots were found in MNC. Significantly different expression of 138 protein spots were identified by LC/MS/MS. Ninety-five secretory proteins in conditioned media of HFB culture system showed a significant 2 -fold increase as compared to those of MNC system. These proteins could be mainly categorized into 6 groups according to their function namely cell cycle, cytoskeleton structure, immune system, metabolic pathway, signaling transduction and ubiquitin-proteasome pathway (Table II). Among these proteins, neutrophil gelatinase-associated lipocalin (NGAL or lipocalin-2) (spot no. 6), pterin-4- $\alpha$-carbinolamine dehydratase (spot no. 55), proteasome subunit $\beta$ type-7 (spot no. 108) and triose phosphate isomerase (spot no. 109) were expressed only in conditioned media of HFB system. Eight interesting proteins showed increased expression by $>10$-fold, while 27 proteins were expressed between 5- and 10-fold higher and 20 proteins were expressed between 2- and 5-fold higher.
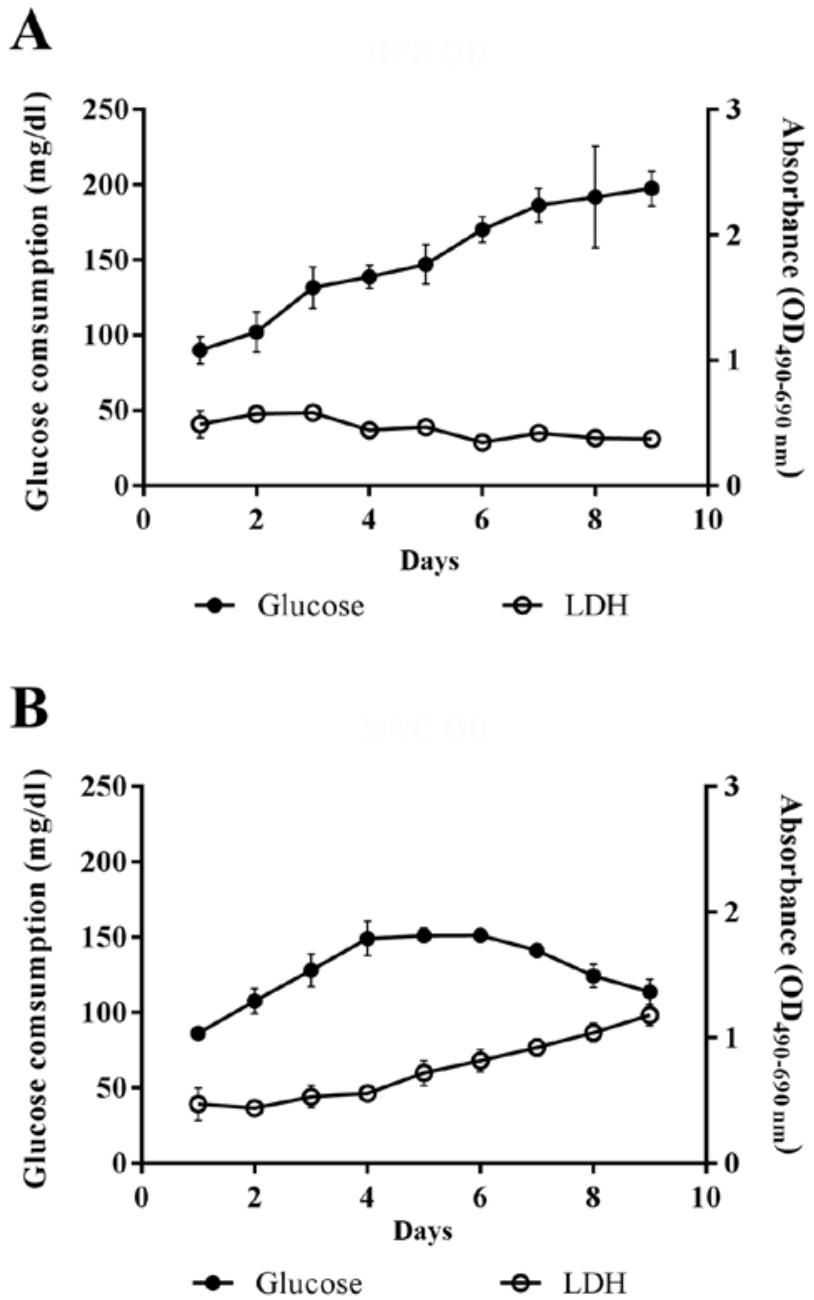

Figure 1. Comparison of glucose consumption and lactate dehydrogenase release in conditioned media from (A) HFB and (B) MNC systems during days 1-9. The data are shown as mean \pm SD of three independent experiments.

NGAL or lipocalin-2 (spot nos. 11 and 66) were found to show the greatest increase in expression by 19.93 -fold and 18.79 fold, and 2 more spots also belong to the same protein (spot nos. 6 and 15) at different pI. Ferritin light chain, ferritin heavy chain, proteasome subunit $\alpha$ type-3, Annexin A3, triose phosphate isomerase and mitochondrial enoyl-CoA $\Delta$ isomerase 1 showed $>10$-fold higher expression. Proteins with 5-10-fold increased expression include macrophage migration inhibitory factor, calmodulin, $60 \mathrm{~S}$ ribosomal protein L12, proteasome subunit $\beta$ type-5, superoxide dismutase $(\mathrm{Mn})$, proteasome subunit $\beta$ type- 1 , proteasome subunit $\beta$ type-7, NGAL, proteasome subunit $\beta$ type- 4 , NAD(P)H-hydrate epimerase, proteasome subunit $\beta$ type-7, proteasome subunit $\alpha$ type-5, complement component $1 \mathrm{Q}, \mathrm{N}(\mathrm{G}), \mathrm{N}(\mathrm{G})$-dimethylarginine dimethylaminohydrolase 1 . Interestingly, the expression levels of all $20 \mathrm{~S}$ proteasome subunits including proteasome subunit $\alpha$ type- 1 to type- 7 and $\beta$ type- 1 to type- 7 were all increased in HFB compared to those in the MNC, with the-fold changes ranging between 2.92 and 12.13 (except for spot no. 108 which was only present in the HFB).

Protein-protein interaction prediction of the proteins from HFB system compared to MNC system. The potential protein 
Table II. Identification of upregulated secretory proteins from HFB culture system by LC-MS/MS.

\begin{tabular}{ccccc}
\hline Spot no. & $\begin{array}{c}\text { Accession } \\
\text { no. }\end{array}$ & Protein description & Score & $\begin{array}{c}\text { Peptide } \\
\text { match }\end{array}$ \\
\end{tabular}

\section{Cell cycle} 72

Q7M4R4
72
72
72
72
72
72

Cytoskeleton structure

$\begin{array}{rc}27 & \text { Q9HC38 } \\ 35 & \text { Q5TCJ2 } \\ 72 & \text { Q9UCS3 } \\ & \text { Q5VU72 } \\ & \text { P07951 } \\ & \text { Q6DV90 } \\ 83 & \text { P13796 } \\ & \text { P60709 } \\ 84 & \text { P23528 } \\ 85 & \text { P23528 } \\ 96 & \text { P18206 } \\ 101 & \text { P07737 }\end{array}$

Immune system

$\begin{aligned} 6 & \text { Q92683 } \\ 11 & \text { Q92683 } \\ 15 & \text { Q92683 } \\ 26 & \text { Q07021 } \\ 66 & \text { Q92683 } \\ 72 & \text { P04083 }\end{aligned}$

Metabolic pathway

$\begin{array}{cc}1 & \text { P14174 } \\ 20 & \text { Q8NCW5 } \\ 26 & \text { P40925 } \\ 28 & \text { O94760 }\end{array}$

P07195

29

O95861

31

P60174

32

P00492

P42126

P78417

P00491

P09972

P16930

49

P17174

Q9Y617

P28838

14-3-3 protein $\varepsilon$
Q7M4R4
Q7M4R4
Q7M4R4
Q7M4R4
Q7M4R4
Q7M4R4

Glyoxalase domain-containing protein 4 Prelamin-A/C

Tropomyosin $\alpha-4$ chain

Tropomyosin $\alpha-3$ chain

Tropomyosin $\beta$ chain

Tropomyosin $\alpha-1$ chain

Plastin-2

Actin, cytoplasmic 1

Cofilin- ${ }^{\text {b }}$

Cofilin- $1^{\mathrm{b}}$

Vinculin

Profilin- $1^{\mathrm{b}}$

$\begin{array}{rc}12 & 29.3 / 4.64 \\ 119 & 12 \\ 119 & 12 \\ 119 & 12 \\ 119 & 12 \\ 119 & 12 \\ 119 & 12\end{array}$

2.75

29.3/4.64

$29.3 / 4.64$

$29.3 / 4.64$

$29.3 / 4.64$

$29.3 / 4.64$

29.3/4.64

$18.5 / 8.22$

Neutrophil gelatinase-associated lipocalin

Neutrophil gelatinase-associated lipocalin

Neutrophil gelatinase-associated lipocalin Complement component $1 \mathrm{Q}$

Neutrophil gelatinase-associated lipocalin Annexin A1

\section{1}

Macrophage migration inhibitory factor NAD(P)H-hydrate epimerase

Malate dehydrogenase, cytoplasmic $\mathrm{N}(\mathrm{G}), \mathrm{N}(\mathrm{G})$-dimethylarginine dimethylaminohydrolase 1

L-lactate dehydrogenase B chain 3'(2'),5'-bisphosphate nucleotidase 1

Triosephosphate isomerase

Hypoxanthine-guanine phosphoribosyltransferase

Enoyl-CoA $\Delta$ isomerase 1, mitochondrial Glutathione S-transferase $\omega-1$

Purine nucleoside phosphorylase

Fructose-bisphosphate aldolase C Fumarylacetoacetase

Aspartate aminotransferase, cytoplasmic

Phosphoserine aminotransferase

Cytosol aminopeptidase
22.7/9.02

INF

18.79

6.36

22.7/9.02

7.11

19.93

2.75

116

92

63

283

53

172

306

195

177

166

50

90

131

58

66

246

$31.7 / 4.74$

22.7/9.02

$32.7 / 4.69$

7.69

7.94

7.11

7.54

7.54

6.26

14.04

7.93

13.34

3.70

8.75

7.78

6.92

6.82

6.82

6.33 
Table II. Continued.

\begin{tabular}{cccc}
\hline $\begin{array}{c}\text { Spot no. } \\
\text { no. }\end{array}$ & Protein description & Score & $\begin{array}{c}\text { Peptide } \\
\text { match }\end{array}$ \\
\hline
\end{tabular}

\begin{tabular}{rl}
\hline 55 & $\mathrm{P} 61457$ \\
58 & $\mathrm{P} 15531$ \\
62 & $\mathrm{P} 09622$ \\
67 & $\mathrm{Q} 6 \mathrm{NR} 85$ \\
68 & $\mathrm{O} 75223$ \\
69 & $\mathrm{Q} 04760$ \\
70 & $\mathrm{Q} 04760$ \\
71 & $\mathrm{P} 00491$ \\
78 & $\mathrm{O} 75874$ \\
& \\
& $\mathrm{P} 48735$ \\
& \\
79 & $\mathrm{P} 06733$ \\
83 & $\mathrm{P} 17174$ \\
91 & $\mathrm{P} 29401$ \\
92 & $\mathrm{P} 06733$ \\
98 & $\mathrm{P} 06733$ \\
99 & $\mathrm{P} 60174$ \\
106 & $\mathrm{P} 18669$ \\
107 & $\mathrm{P} 48637$ \\
109 & $\mathrm{Q} 9 \mathrm{Y} 2 \mathrm{~T} 3$ \\
110 & $\mathrm{P} 60174$ \\
& $\mathrm{P} 06733$ \\
&
\end{tabular}

Pterin-4- $\alpha$-carbinolamine dehydratase

Nucleoside diphosphate kinase A

Dihydrolipoyl dehydrogenase, mitochondrial

Superoxide dismutase $(\mathrm{Cu}-\mathrm{Zn})$ $\gamma$-glutamylcyclotransferase

Lactoylglutathione lyase

Lactoylglutathione lyase

Purine nucleoside phosphorylase

Isocitrate dehydrogenase (NADP),

cytoplasmic

Isocitrate dehydrogenase (NADP),

mitochondrial

$\alpha$-enolase

Aspartate aminotransferase, cytoplasmic

Transketolase

$\alpha$-enolase ${ }^{b}$

$\alpha$-enolase ${ }^{b}$

Triosephosphate isomerase $^{b}$

Phosphoglycerate mutase $1^{\text {b }}$

Glutathione synthetase

Guanine deaminase

Triosephosphate isomerase $\alpha$-enolase

Protein S100-A11
Cystatin-B
Cystatin- $B^{\mathrm{b}}$

P04080

101

P04080

Peroxisome

12

13

14

39

42
Q5TCM1 Superoxide dismutase (Mn), mitochondrial

Q5TCM1 Superoxide dismutase (Mn), mitochondrial

Q5TCM1 Superoxide dismutase (Mn), mitochondrial

Q13011

Q13011

$\Delta(3,5)-\Delta(2,4)$-dienoyl-CoA isomerase, mitochondrial

$\Delta(3,5)-\Delta(2,4)$-dienoyl-CoA isomerase, mitochondrial

Signal transduction

$\begin{array}{rc}2 & \mathrm{P} 06703 \\ 3 & \mathrm{P} 06703 \\ & \mathrm{P} 29034 \\ 4 & \mathrm{Q} 96 \mathrm{HK} 3 \\ 5 & \mathrm{Q} 96 \mathrm{HK} 3 \\ 12 & \mathrm{P} 43487 \\ 26 & \mathrm{P} 07355 \\ 27 & \mathrm{P} 12429 \\ 95 & \mathrm{P} 12429 \\ 89 & \mathrm{P} 60903 \\ 97 & \mathrm{P} 04792 \\ 06 & \mathrm{P} 07339\end{array}$

$$
\begin{gathered}
\text { Protein S100-A6 } \\
\text { Protein S100-A6 } \\
\text { Protein S100-A2 } \\
\text { Calmodulin } \\
\text { Calmodulin }
\end{gathered}
$$

Ran-specific GTPase-activating protein

Annexin A2

Annexin A3

Annexin $\mathrm{A} 3^{\mathrm{b}}$

Protein S100-A $10^{\mathrm{b}}$

Heat shock protein $\beta-1^{b}$

Cathepsin D
148

53
803
71
139
54
934
786
72
648
477
277
504

\section{3}

80

303

71

139

54

93

234

206

78

72

288

64

-

$-$

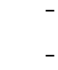

504

467

411

277

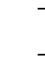

83

77

53

140

181

76

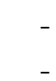

113

$\begin{array}{rcc}1 & 12.0 / 6.28 & \text { INF } \\ 2 & 17.3 / 5.83 & 3.96 \\ 5 & 54.7 / 7.95 & 5.61 \\ & & \\ 1 & 16.2 / 5.7 & 9.04 \\ 3 & 21.2 / 5.07 & 3.07 \\ 1 & 21.0 / 5.12 & 2.92 \\ 5 & 21.0 / 5.12 & 3.53 \\ 5 & 32.3 / 6.45 & 7.29 \\ 5 & 46.9 / 6.53 & 5.92 \\ & & \\ 3 & 51.3 / 8.88 & 5.92 \\ & & \\ 1 & 47.5 / 7.01 & 5.92 \\ 9 & 46.4 / 6.52 & 9.76 \\ 2 & 68.5 / 7.58 & 4.46 \\ - & 47.5 / 7.01 & 7.73 \\ - & 47.5 / 7.01 & 7.07 \\ - & 31.1 / 5.65 & 6.18 \\ - & 28.8 / 6.67 & 11.46 \\ 10 & 52.5 / 5.67 & 5.01 \\ 8 & 51.5 / 5.44 & 8.47 \\ 7 & 31.1 / 5.65 & \text { INF } \\ 7 & 47.5 / 7.01 & \text { INF }\end{array}$

$\begin{array}{lcr}3 & 11.8 / 6.56 & 2.49 \\ - & 11.13 / 6.96 & 11.76 \\ - & 11.13 / 6.96 & 10.08\end{array}$

$3 \quad 24.9 / 8.35$

5.97

6.55

8.50

4.97

$2 \quad 36.1 / 8.16$

7.67 
Table II. Continued.

\begin{tabular}{|c|c|c|c|c|c|c|}
\hline Spot no. & $\begin{array}{c}\text { Accession } \\
\text { no. }\end{array}$ & Protein description & Score & $\begin{array}{l}\text { Peptide } \\
\text { match }\end{array}$ & $\mathrm{MW} / \mathrm{pI}$ & Fold change $^{\mathrm{a}}$ \\
\hline
\end{tabular}

$\begin{array}{rr}\text { Ubiquitin-proteasome p } \\ 10 & \mathrm{P} 28074 \\ 12 & \mathrm{P} 20618 \\ 13 & \mathrm{P} 49721 \\ 14 & \mathrm{P} 49721 \\ & \mathrm{Q} 99436 \\ & \mathrm{P} 20618 \\ 18 & \mathrm{P} 28070 \\ 21 & \mathrm{Q} 99436 \\ 22 & \mathrm{P} 25788 \\ 23 & \mathrm{P} 28066 \\ 30 & \mathrm{P} 25787 \\ 33 & \mathrm{P} 60900 \\ 34 & \mathrm{P} 49720 \\ 36 & \mathrm{P} 60900 \\ 39 & \mathrm{P} 25786 \\ 41 & \mathrm{P} 25786 \\ 44 & \mathrm{O} 14818 \\ 45 & \mathrm{P} 25789 \\ 65 & \mathrm{P} 55072 \\ 69 & \mathrm{P} 28072 \\ 101 & \mathrm{P} 05161 \\ 108 & \mathrm{Q} 99436\end{array}$

Others

\begin{tabular}{rcc}
4 & P37108 & Signal recognition particle 14 kDa protein \\
5 & P30050 & 60S ribosomal protein L12 \\
7 & Q9BTZ8 & Ferritin light chain \\
8 & P02794 & Ferritin heavy chain \\
& Q8NBP7 & Proprotein convertase subtilisin/kexin type 9 \\
9 & P02794 & Ferritin heavy chain \\
16 & Q99497 & Protein deglycase DJ-1 \\
48 & Q9UC56 & Stress-70 protein, mitochondrial \\
64 & P13798 & Acylamino-acid-releasing enzyme \\
75 & O75340 & Programmed cell death protein 6 \\
81 & P02794 & Ferritin heavy chain \\
83 & P02768 & Serum albumin \\
94 & P27797 & Calreticulin \\
96 & P00738 & Haptoglobin \\
100 & Q04837 & Single-stranded DNA-binding protein, \\
& & mitochondrial \\
102 & O60739 & Eukaryotic translation initiation factor 1b \\
103 & Q99497 & Protein deglycase DJ-1 \\
107 & P68871 & Hemoglobin subunit $\beta$ \\
108 & P16083 & Ribosyldihydronicotinamide dehydrogenase \\
& & (quinone) \\
\hline
\end{tabular}

Proteasome subunit $\beta$ type-5

Proteasome subunit $\beta$ type-1

Proteasome subunit $\beta$ type-2

Proteasome subunit $\beta$ type- 2

Proteasome subunit $\beta$ type-7

Proteasome subunit $\beta$ type- 1

Proteasome subunit $\beta$ type- 4

Proteasome subunit $\beta$ type-7

Proteasome subunit $\alpha$ type- 3

Proteasome subunit $\alpha$ type-5

Proteasome subunit $\alpha$ type- 2

Proteasome subunit $\alpha$ type- 6

Proteasome subunit $\beta$ type- 3

Proteasome subunit $\alpha$ type- 6

Proteasome subunit $\alpha$ type- 1

Proteasome subunit $\alpha$ type- 1

Proteasome subunit $\alpha$ type-7

Proteasome subunit $\alpha$ type- 4

Transitional endoplasmic reticulum ATPase

Proteasome subunit $\beta$ type- 6

Ubiquitin-like protein ISG15

Proteasome subunit $\beta$ type-7

146

71

51

329

70

68

231

108

149

324

109

91

150

110

159

119

201

194

236

131

346

164

54

63

84

102

52

119

51

163

67

120

59

277

-

50

179

-
265
137
103

28.6/6.43

7.07

5.97

6.55

8.50

8.50

8.50

7.22

8.61

12.13

5.27

4.91

3.08

8.54

7.65

4.97

5.66

7.36

6.33

4.16

2.92

11.76

INF

$30.3 / 7.57$

4.10

6.19

10.74

9.13

9.13

1.50

3.85

8.72

3.81

2.11

2.44

4.46

5.46

4.87

4.83

$17.2 / 9.59$

10.08

10.69

8.47

INF

${ }^{a}$ Fold change is the ratio between the mean volume levels of the secreted proteins from HFB system and from MNC system. ${ }^{\mathrm{b}}$ The mapping spot with in house database. INF, no available data due to the absence of protein spots from MNC system. MW, molecular weight. pI, isoelectric point. 

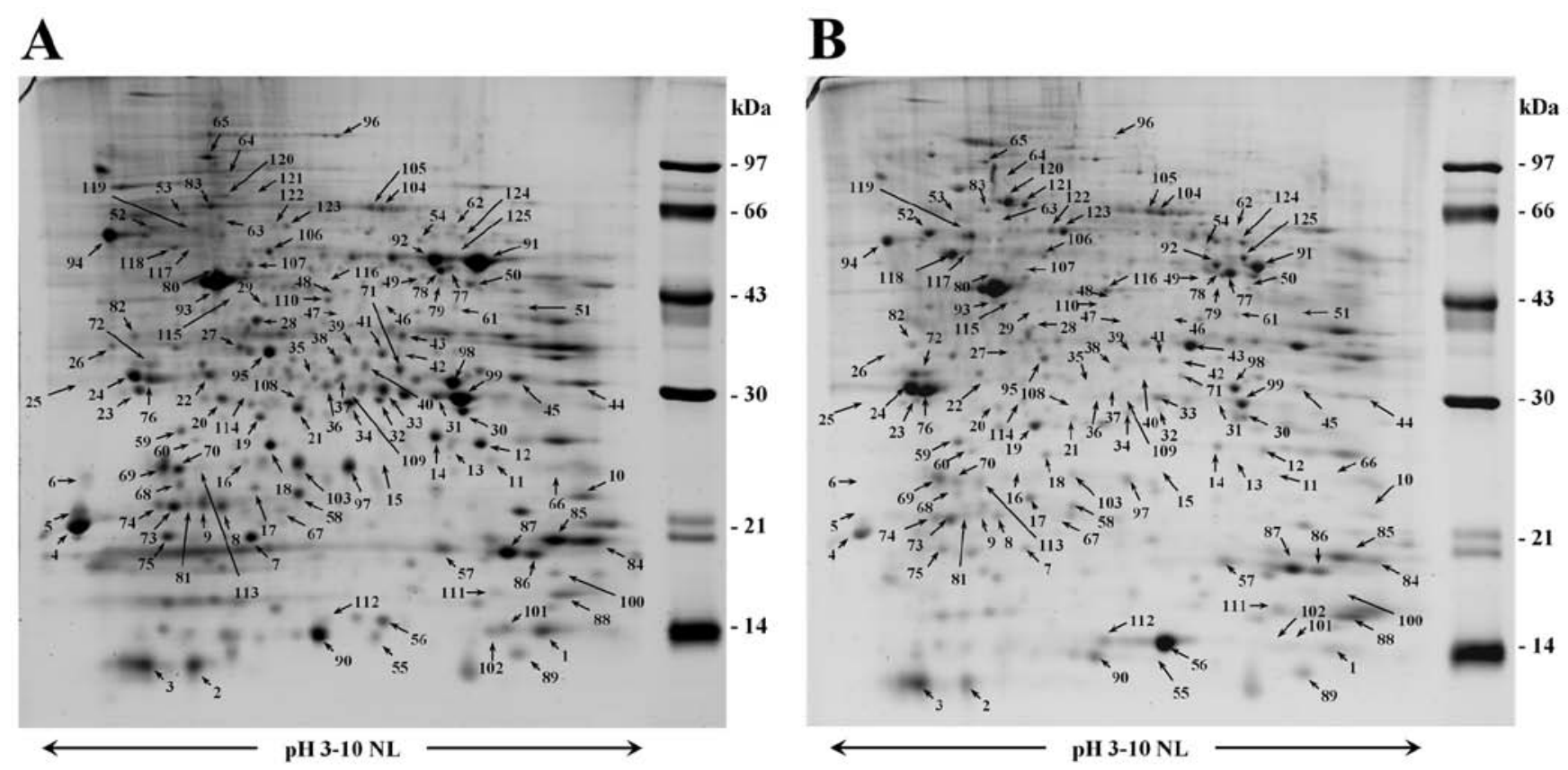

Figure 2. Representative 2DE profiles of secreted proteins from (A) HFB and (B) MNC systems separated by non-linear IEF at pH 3-10 and 12.5\% SDS-polyacrylamide gel. Arrows indicate differentially expressed spots identified by LC/MS/MS .

interactions were predicted by a bioinformatics program (STRING). The analysis was performed on 95 proteins with 2-fold higher expression in the HFB system when compared to those in the MNC system. Upregulated proteins were selected for this analysis because they should be more suitable as for potential biomarkers (22). The upregulated proteins could form at least three clusters of the interaction networks as shown in Fig. 3. The first cluster (purple background) belongs to the $20 \mathrm{~S}$ proteasome subunits including proteasome subunit $\alpha$ type-1 to type-7 (PSMA1-7) and $\beta$ type-1 to type-7 (PSMB1-7) which, according to the KEGG pathway (23), is involved in the regulation of various functions. The proteins associated in cell cycle pathway are the 14-3-3 protein family including 14-3-3 protein $\varepsilon$ (YWHAE), 14-3-3 protein $\sigma$ (SFN), 14-3-3 protein $\beta / \alpha$ (YWHAB), 14-3-3 protein $\gamma$ (YWHAG), 14-3-3 protein $\eta$ (YWHAH), 14-3-3 protein $\theta$ (YWHAQ) are shown in the second cluster (red background). The third cluster (green background) are proteins involved in metabolism including glycolysis/gluconeogenesis, citrate cycle (TCA cycle), pyruvate metabolism, 2-oxocarboxylic acid metabolism, cysteine and methionine metabolism, tyrosine metabolism, glycine, serine and threonine metabolism, and phenylalanine metabolism.

Validation of identified proteins by western blotting. According to the results from 2DE and prediction of protein-protein interactions, 95 secretory proteins from HFB system were significantly increased and can be clustered as a functional relationship into 3 groups as compared with MNC system. Immunodetection was further used to validate some distinct secreted proteins that may be useful for cancer biomarker study including NGAL, PSMA6, PSMB6, PSMA3, LCP1, DJ-1, TPI, and ENO1 as shown in Fig. 4. In agreement with 2DE results, western blot analyses revealed that the expression levels of these proteins were significantly increased in the HFB system compared to those in the MNC system. Interestingly, among of these secreted proteins, only $20 \mathrm{~S}$ proteasome has never been proposed as a potential biomarker for early detection in cholangiocarcinoma.

Proteasome activity assay. Proteasomes function mainly inside the cells, therefore, we next studied whether the identified $20 \mathrm{~S}$ proteasome subunits present in the extracellular compartment had active functions. The activity of the $20 \mathrm{~S}$ proteasome was therefore studied in conditioned media from both HFB and MNC systems. Cumulative fluorescent signals from the proteasomal-related proteolytic activity were detected in conditioned media from both HFB and MNC systems (Fig. 5A). This indicated the $20 \mathrm{~S}$ proteasome subunits secreted from cells were still active in function. Consistent with the immunodetection results, higher proteasome activity was observed in conditioned media of HFB system in comparison to that of MNC system. Proteasomal specific activity of HFB and MNC samples were 38.63 and $17.22 \mathrm{U} / \mu \mathrm{g}$, respectively (Fig. 5A). In addition, the proteasome activities were also investigated in the conditioned media from HuCCA-1 and HCC-S102, with the result that the proteasome activity of HuCCA-1 secretome was higher than that of HCC-S102 secretome (42.63 and 30.78 $\mathrm{U} / \mu \mathrm{g}$, respectively) (Fig. 5B).

Confirmation of proteasome subunit a type-3 on cholangiocarcinoma plasma samples. To validate $20 \mathrm{~S}$ proteasome as potential biomarker for CCA, the level of plasma PSMA3 was measured using western blot analysis in normal donor $(n=5)$, in CCA patients with stage I $(n=1)$, stage III $(n=2)$, stage IV $(n=1)$, in HCC patients with stage I $(n=1)$ and stage III $(n=2)$. To enrich low-abundance proteins, human plasma albumin and $\operatorname{IgG}$ was removed prior to immunodetection. PSMA3 were detected in blood plasma from normal subjects, CCA and HCC patients (Fig. 6A). Interestingly, plasma PSMA3 of CCA patients were significantly increased as compared 


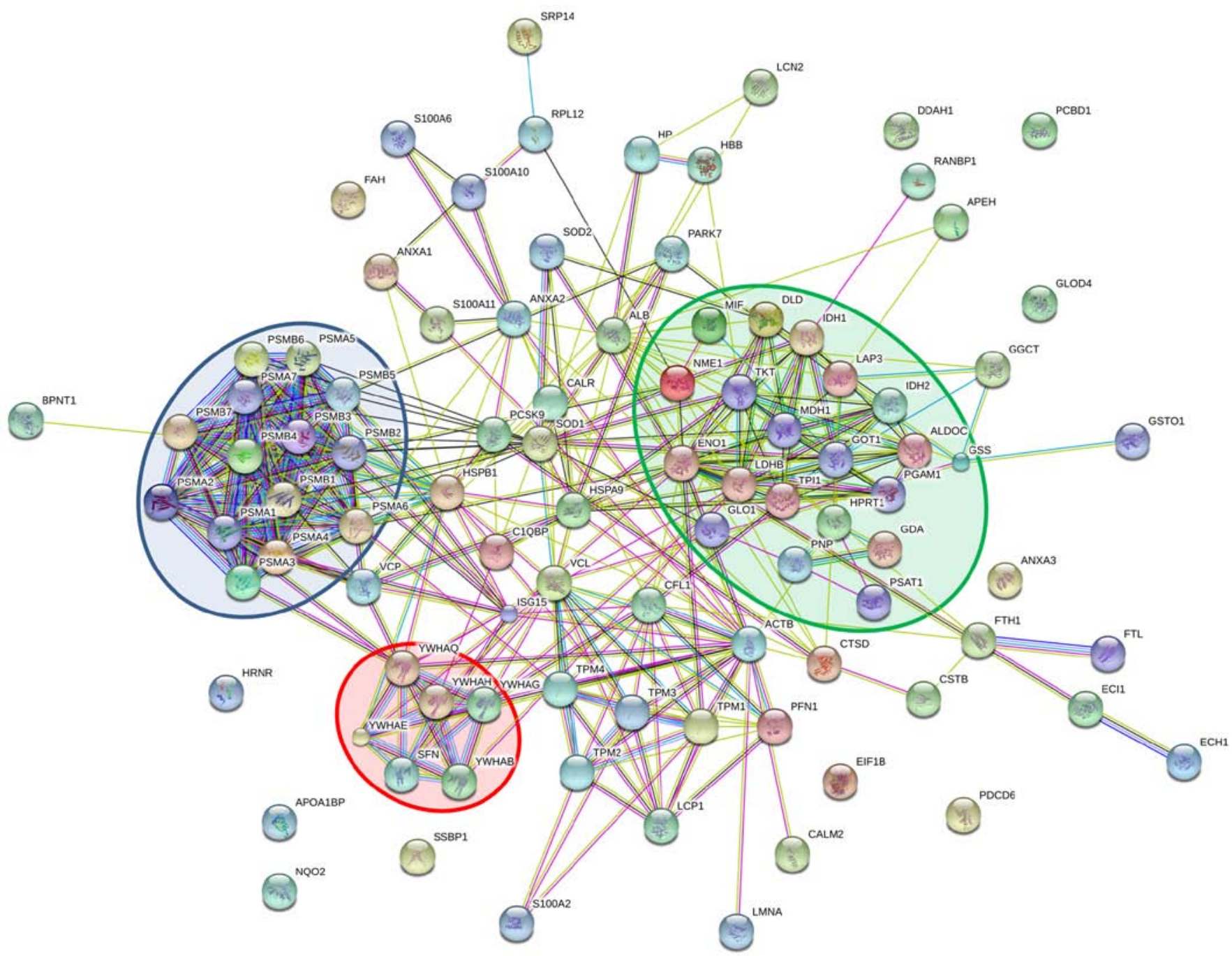

Figure 3. STRING analysis of 95 proteins significantly increased in HFB system as compared to MNC system (>2-fold changes). The interaction networks can be divided into three major clusters, namely proteins related in metabolic pathways (green background), 20S proteasome core subunits (blue background), and cell cycle pathways (red background).

$\mathbf{A}$

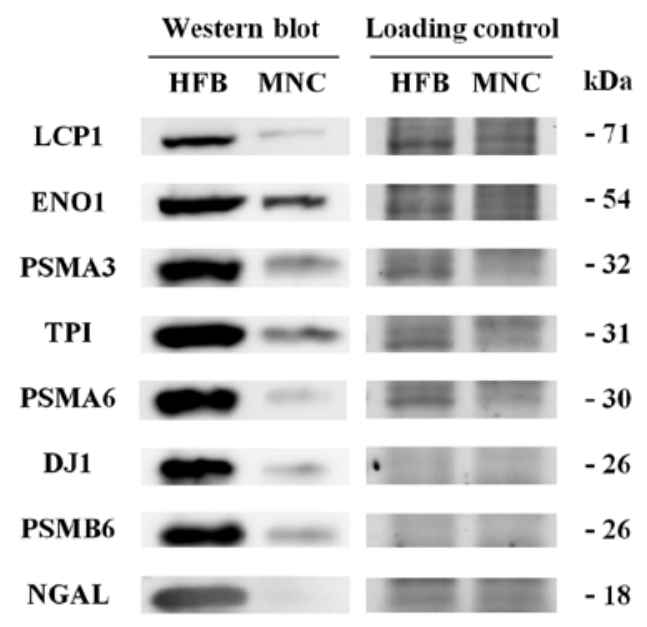

\section{B}

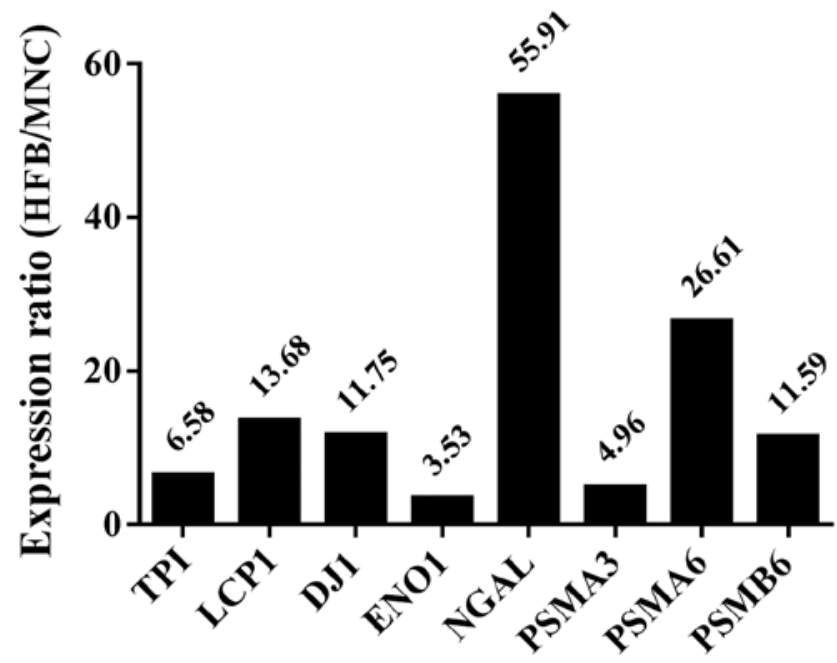

Figure 4. (A) Western blot detection of secretory proteins from HFB and MNC systems. Results show enrichment of secretory LCP1, ENO1, PSMA3 TPI, PSMA6, DJ1, PSMB6 and NGAL in the HFB system. The loading control was obtained by subsequently staining the membrane with Coomassie blue after the western blotting. (B) Bar graphs represent the expression ratio of the protein intensity (HFB/MNC) detected by western blotting shown as the number values on the top of each bar. 
A

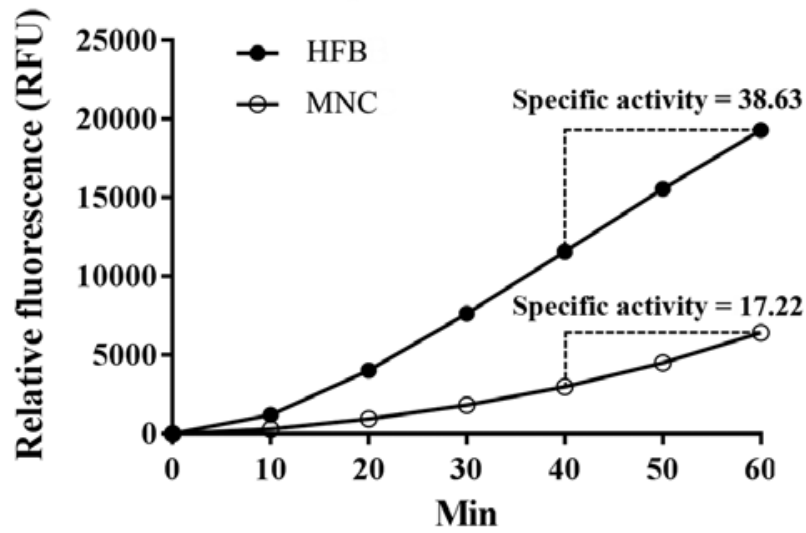

B

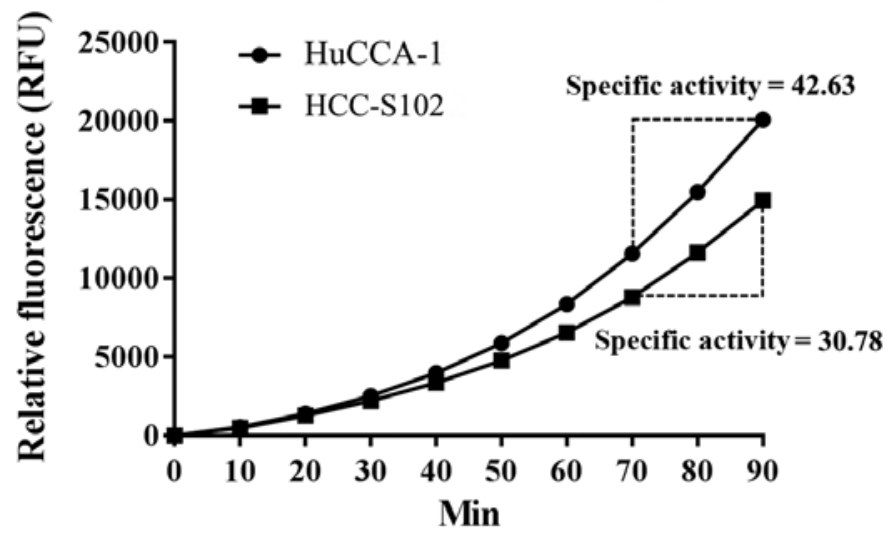

Figure 5. Kinetic study of proteasome activity from cellular secretions. (A) Comparison of HuCCA-1 proteasome activity in conditioned media between HFB and MNC systems. (B) Comparison of proteasome activity of secreted proteins derived from MNC system of HuCCA-1 and HCC-S102. Graphs represent the relative fluorescent units (RFU) at various time-points.

A

WB: PSMA3

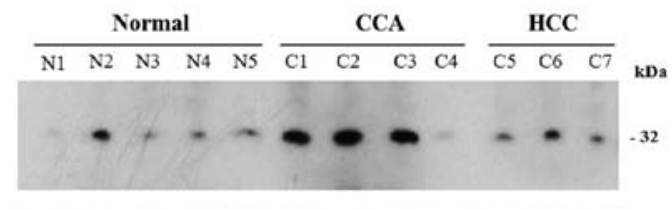

Loading control

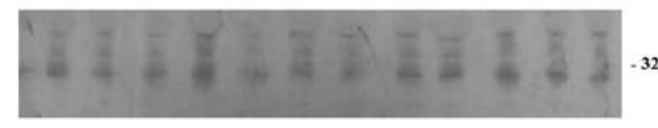

\section{B}

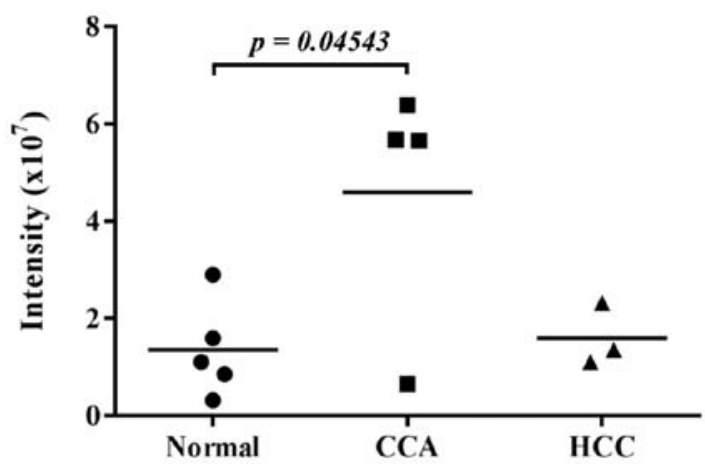

Figure 6. (A) Western blot analysis of plasma PSMA3 levels in the control group (normal; $n=5)$, cholangiocarcinoma patients $(\mathrm{CCA} ; \mathrm{n}=4)$ and hepatocellular carcinoma patients $(\mathrm{HCC} ; \mathrm{n}=3)$. (B) The data are shown as scatter plots with horizontal line representing the mean plasma PSMA3 intensity band from western blot analysis. Statistical analysis (p-value) was calculated by one-way ANOVA with post hoc Tukey HSD analysis.

to normal subjects. The levels of PSMA3 were obviously increased in the plasma of CCA patients as compared to HCC patients (Fig. 6B). Moreover, the levels of plasma PSMA3 were significantly elevated in cancer patients with stage III and IV compared to normal subjects (Fig. 6B).

\section{Discussion}

The secretome is a useful source to identify novel circulating biomarkers in blood secreted from cancer cells. The main challenges in secretomic analysis are the complexity of sample preparation, serum proteins and importantly cell lysate contamination. In this study, we have developed the hollow fiber bioreactor system for 3-D culture of cholangiocarcinoma cells by using a 5-kDa MWCO instead of a 20-kDa MWCO cartridge. In agreement with our previous study (12), the HFB culture system (5 kDa MWCO cartridge) also provides enrichment of low-abundance secretory proteins by reducing the level of cellular protein contamination. The protein expression from HFB system was compared to that from the monolayer system. The most highly expressed protein was NGAL or lipocalin-2, which was previously reported by us (10). NGAL is a secreted protein, a member of the lipocalin superfamily involved in various functions, such as a factor in the innate immune system, transport of hydrophobic substances, iron delivery and apoptosis-dependent deprivation of trophic factor. It was also reported to be a potential biomarker for many cancers, such as pancreatic, ovarian and colorectal cancer (24-26). We also reported the possibility of using NGAL as a potential biomarker for cholangiocarcinoma by immunoblotting of the tissues from cancer patients. We have also used western blot analysis to validate the NGAL from conditioned media and to confirm its presence in plasma of cancer patients (unpublished data). Our result corresponds to a recent report on lipocalin-2 as a potential biomarker for CCA (27).

The number of proteins associated with metabolic pathways, especially TPI and ENO1, was also increased in conditioned media from HFB culture system in comparison with that from the MNC system. TPI is a glycolytic enzyme that catalyzes the reversible conversion of dihydroxyacetone phosphate (DHAP) into D-glyceraldehyde 3-phosphate (G3P), which maintains the equilibrium between these two triose phosphates (28). Upregulation of TPI have been found in metastatic tissues of various cancers, such as breast cancer (29), brain metastases from endometrial and ovarian cancer (30). Another elevated secretory glycolytic enzyme in the HFB culture system is ENO1 that converts 2-phosphoglycerate (2-PG) to phosphoenolpyruvate (PEP) in the glycolysis pathway (31). Growing evidence suggests that, apart from its majority role in 
glycolysis, ENO1 can also function as an oncogenic protein by promoting the proliferation, invasion and metastasis of tumor cells (32-35). Therefore, the expression of ENO1 is frequently increased in diverse tumors (36) including CCA (37).

Additionally, the levels of secretory 14-3-3 protein were significantly increased in the HFB system compared to the MNC system. The 14-3-3 protein is an intracellular phosphoserine/threonine binding protein that is involved in many biological processes including cell cycle regulation, protein trafficking, metabolic regulation, cell proliferation, and apoptosis. Not surprisingly, significant roles of 14-3-3 have also been found in various cancer types including CCA (38). In colorectal carcinoma, 14-3-3 $\sigma$ expression is reported to be increased during carcinoma progression. Moreover, the overexpression of 14-3-3 $\sigma$ is associated with significantly reduced survival duration in these patients (39). Increasing number of studies suggest that 14-3-3 play a critical role during cancer metastasis in HCC (40). We recently reported the upregulation of 14-3-3 $\sigma$ protein that plays an important role in anoikis resistance of human CCA cells (41). In addition, the secretory 14-3-3o protein in the conditioned media of $3 \mathrm{D}$ culture systems is significantly increased compared to those of MNC culture system $(11,12)$.

A major finding using the 5-kDa MWCO cartridge with the HFB system was the expression of the $20 \mathrm{~S}$ proteasome, a catalytic portion of $26 \mathrm{~S}$ proteasome (13), including proteasome subunit $\alpha$ type- 1 to type- 7 and $\beta$ type- 1 to type- 7 . The proteasome activity results indicated that all of these subunits were secreted and still active. The $20 \mathrm{~S}$ proteasome plays important roles in degradation of proteins that no longer are needed, or fail to fold correctly (42). Accumulating evidence suggests that increase of proteasome activity and the high expression of proteasome subunits can be observed in various types of cancer (14-16). A high concentration of extracellular proteasome was also found in blood plasma of several cancer patients $(18,43,44)$. Cell damage and hemolysis are considered as the major sources of the elevated extracellular proteasome (17). However, our LDH release results with the HFB system would suggest that cell damage might not be a major source of extracellular $20 \mathrm{~S}$ proteasome. In addition, the level of circulating $20 \mathrm{~S}$ proteasome subunits in serum may be related to the stage of malignancy. Thus, Stoebner et al reported that the proteasome level was increased by up to 4.5 times in serum of patients with metastatic malignant melanoma (stage III and IV) compared to the control group, while proteasome levels in stage I and II patients were not significantly different from healthy subjects (18). In agreement with this, our results showed that the levels of PSMA3 were significantly increased in the plasma of CCA patients at advanced stage as compared to healthy subjects. Moreover, plasma PSMA3 levels were significantly elevated in CCA patients in comparison with HCC patients.

In conclusion, we have demonstrated that the HFB culture system provides improved enrichment of the low-abundance secreted proteins from CCA cells, compared to conventional monolayer culture, and reduces the cellular protein contamination. This enrichment of low-abundance secreted proteins opens up the discovery of a novel biomarker PSMA3 for CCA. Elevated levels of plasma PSMA3 were detected in patients with metastatic cancer, especially at advanced stage, as compared to healthy subjects. Moreover, PSMA3 was found at high levels in plasma of CCA patients, as compared to normal subjects and $\mathrm{HCC}$ patients. These finding indicated that plasma PSMA3 might represent a novel biomarker for CCA.

\section{Acknowledgements}

This study was supported by the Chulabhorn Research Institute (grant no. BC 2008-02). We would like to thank Dr Vichien Chaousrikul for his work on histopathologic diagnosis of cholangiocarcinoma, and Mr. Thongsuk Pobboon, Ms. Nittaya Therawattanakul and Ms. Sirimon Damri for their technical assistance.

\section{References}

1. Ghouri YA, Mian I and Blechacz B: Cancer review: Cholangiocarcinoma. J Carcinog 14: 1, 2015.

2. Sonakul D, Koompirochana C, Chinda K and Stitnimakarn T: Hepatic carcinoma with opisthorchiasis. Southeast Asian J Trop Med Public Health 9: 215-219, 1978.

3. Björnsson E, Kilander A and Olsson R: CA 19-9 and CEA are unreliable markers for cholangiocarcinoma in patients with primary sclerosing cholangitis. Liver 19: 501-508, 1999.

4. Qin XL, Wang ZR, Shi JS, Lu M, Wang L and He QR: Utility of serum CA19-9 in diagnosis of cholangiocarcinoma: In comparison with CEA. World J Gastroenterol 10: 427-432, 2004.

5. Lumachi F, Lo Re G, Tozzoli R, D'Aurizio F, Facomer F, Chiara GB and Basso SM: Measurement of serum carcinoembryonic antigen, carbohydrate antigen 19-9, cytokeratin-19 fragment and matrix metalloproteinase-7 for detecting cholangiocarcinoma: A preliminary case-control study. Anticancer Res 34: 6663-6667, 2014.

6. Shigehara K, Yokomuro S, Ishibashi O, Mizuguchi Y, Arima Y, Kawahigashi Y, Kanda T, Akagi I, Tajiri T, Yoshida H, et al: Real-time PCR-based analysis of the human bile microRNAome identifies miR-9 as a potential diagnostic biomarker for biliary tract cancer. PLoS One 6: e23584, 2011.

7. Mott JL and Gores GJ: Targeting IL-6 in cholangiocarcinoma therapy. Am J Gastroenterol 102: 2171-2172, 2007.

8. Shen J, Wang W, Wu J, Feng B, Chen W, Wang M, Tang J, Wang F, Cheng F, Pu L, et al: Comparative proteomic profiling of human bile reveals SSP411 as a novel biomarker of cholangiocarcinoma. PLoS One 7: e47476, 2012.

9. Chang YH, Wu CC, Chang KP, Yu JS, Chang YC and Liao PC: Cell secretome analysis using hollow fiber culture system leads to the discovery of CLIC1 protein as a novel plasma marker for nasopharyngeal carcinoma. J Proteome Res 8: 5465-5474, 2009.

10. Srisomsap C, Sawangareetrakul $P$, Subhasitanont $P$, Chokchaichamnankit D, Chiablaem K, Bhudhisawasdi V, Wongkham S and Svasti J: Proteomic studies of cholangiocarcinoma and hepatocellular carcinoma cell secretomes. J Biomed Biotechnol 2010: 437143, 2010.

11. Tit-Oon P, Chokchaichamnankit D, Khongmanee A, Sawangareetrakul P, Svasti J and Srisomsap C: Comparative secretome analysis of cholangiocarcinoma cell line in threedimensional culture. Int J Oncol 45: 2108-2116, 2014.

12. Weeraphan C, Diskul-Na-Ayudthaya P, Chiablaem K, Khongmanee A, Chokchaichamnankit D, Subhasitanont P, Svasti J and Srisomsap C: Effective enrichment of cholangiocarcinoma secretomes using the hollow fiber bioreactor culture system. Talanta 99: 294-301, 2012

13. Unno M, Mizushima T, Morimoto Y, Tomisugi Y, Tanaka K, Yasuoka $\mathrm{N}$ and Tsukihara T: The structure of the mammalian $20 \mathrm{~S}$ proteasome at 2.75 A resolution. Structure 10: 609-618, 2002.

14. Vangala JR, Dudem S, Jain N and Kalivendi SV: Regulation of PSMB5 protein and $\beta$ subunits of mammalian proteasome by constitutively activated signal transducer and activator of transcription 3 (STAT3): Potential role in bortezomib-mediated anticancer therapy. J Biol Chem 289: 12612-12622, 2014.

15. Chen L and Madura K: Increased proteasome activity, ubiquitinconjugating enzymes, and eEF1A translation factor detected in breast cancer tissue. Cancer Res 65: 5599-5606, 2005. 
16. Bazzaro M, Lee MK, Zoso A, Stirling WL, Santillan A, Shih IeM and Roden RB: Ubiquitin-proteasome system stress sensitizes ovarian cancer to proteasome inhibitor-induced apoptosis. Cancer Res 66: 3754-3763, 2006.

17. Sixt SU and Dahlmann B: Extracellular, circulating proteasomes and ubiquitin - incidence and relevance. Biochim Biophys Acta 1782: 817-823, 2008.

18. Stoebner PE, Lavabre-Bertrand T, Henry L, Guiraud I, Carillo S, Dandurand M, Joujoux JM, Bureau JP and Meunier L: High plasma proteasome levels are detected in patients with metastatic malignant melanoma. Br J Dermatol 152: 948-953, 2005.

19. Sirisinha S, Tengchaisri T, Boonpucknavig S, Prempracha N, Ratanarapee S and Pausawasdi A: Establishment and characterization of a cholangiocarcinoma cell line from a Thai patient with intrahepatic bile duct cancer. Asian Pac J Allergy Immunol 9: 153-157, 1991

20. Laohathai K and Bhamarapravati N: Culturing of human hepatocellular carcinoma. A simple and reproducible method. Am J Pathol 118: 203-208, 1985.

21. Srisomsap C, Sawangareetrakul P, Subhasitanont P, Panichakul T, Keeratichamroen S, Lirdprapamongkol K, Chokchaichamnankit D, Sirisinha $S$ and Svasti J: Proteomic analysis of cholangiocarcinoma cell line. Proteomics 4: 1135-1144, 2004.

22. Iuga C, Seicean A, Iancu C, Buiga R, Sappa PK, Völker U and Hammer E: Proteomic identification of potential prognostic biomarkers in resectable pancreatic ductal adenocarcinoma. Proteomics 14: 945-955, 2014.

23. Kanehisa M, Sato Y, Kawashima M, Furumichi M and Tanabe M: KEGG as a reference resource for gene and protein annotation. Nucleic Acids Res 44D: D457-D462, 2016.

24. Tong Z, Kunnumakkara AB, Wang H, Matsuo Y, Diagaradjane P, Harikumar KB, Ramachandran V, Sung B, Chakraborty A, Bresalier RS, et al: Neutrophil gelatinase-associated lipocalin: A novel suppressor of invasion and angiogenesis in pancreatic cancer. Cancer Res 68: 6100-6108, 2008

25. Lim R, Ahmed N, Borregaard N, Riley C, Wafai R, Thompson EW, Quinn MA and Rice GE: Neutrophil gelatinaseassociated lipocalin (NGAL) an early-screening biomarker for ovarian cancer: NGAL is associated with epidermal growth factor-induced epithelio-mesenchymal transition. Int $\mathrm{J}$ Cancer 120: 2426-2434, 2007.

26. Fung KY, Priebe I, Purins L, Tabor B, Brierley GV, Lockett T, Nice E, Gibbs P, Tie J, McMurrick P, et al: Performance of serum lipocalin 2 as a diagnostic marker for colorectal cancer. Cancer Biomark 13: 75-79, 2013.

27. Chiang KC, Yeh TS, Wu RC, Pang JS, Cheng CT, Wang SY, Juang $\mathrm{HH}$ and Yeh CN: Lipocalin 2 (LCN2) is a promising target for cholangiocarcinoma treatment and bile LCN2 level is a potential cholangiocarcinoma diagnostic marker. Sci Rep 6 : 36138, 2016.

28. Mukai C, Gao L, Bergkvist M, Nelson JL, Hinchman MM and Travis AJ: Biomimicry enhances sequential reactions of tethered glycolytic enzymes, TPI and GAPDHS. PLoS One 8: e61434, 2013.

29. Thongwatchara P, Promwikorn W, Srisomsap C, Chokchaichamnankit D, Boonyaphiphat $\mathrm{P}$ and Thongsuksai $\mathrm{P}$. Differential protein expression in primary breast cancer and matched axillary node metastasis. Oncol Rep 26: 185-191, 2011.
30. Yoshida A, Okamoto N, Tozawa-Ono A, Koizumi H, Kiguchi K, Ishizuka B, Kumai T and Suzuki N: Proteomic analysis of differential protein expression by brain metastases of gynecological malignancies. Hum Cell 26: 56-66, 2013.

31. Kang HJ, Jung SK, Kim SJ and Chung SJ: Structure of human alpha-enolase (hENO1), a multifunctional glycolytic enzyme. Acta Crystallogr D Biol Crystallogr 64: 651-657, 2008.

32. He P, Naka T, Serada S, Fujimoto M, Tanaka T, Hashimoto S, Shima Y, Yamadori T, Suzuki H, Hirashima T, et al: Proteomicsbased identification of alpha-enolase as a tumor antigen in non-small lung cancer. Cancer Sci 98: 1234-1240, 2007.

33. Cappello P, Rolla S, Chiarle R, Principe M, Cavallo F, Perconti G, Feo S, Giovarelli M and Novelli F: Vaccination with ENO1 DNA prolongs survival of genetically engineered mice with pancreatic cancer. Gastroenterology 144: 1098-1106, 2013.

34. Wygrecka M, Marsh LM, Morty RE, Henneke I, Guenther A, Lohmeyer J, Markart P and Preissner KT: Enolase-1 promotes plasminogen-mediated recruitment of monocytes to the acutely inflamed lung. Blood 113: 5588-5598, 2009.

35. Fu QF, Liu Y, Fan Y, Hua SN, Qu HY, Dong SW, Li RL, Zhao MY, Zhen Y, Yu XL, et al: Alpha-enolase promotes cell glycolysis, growth, migration, and invasion in non-small cell lung cancer through FAK-mediated PI3K/AKT pathway. J Hematol Oncol 8: $22,2015$.

36. Capello M, Ferri-Borgogno S, Cappello $P$ and Novelli F: $\alpha$-Enolase: A promising therapeutic and diagnostic tumor target. FEBS J 278: 1064-1074, 2011.

37. Yonglitthipagon P, Pairojkul C, Bhudhisawasdi V, Mulvenna J, Loukas A and Sripa B: Proteomics-based identification of $\alpha$-enolase as a potential prognostic marker in cholangiocarcinoma. Clin Biochem 45: 827-834, 2012.

38. Freeman AK and Morrison DK: 14-3-3 Proteins: Diverse functions in cell proliferation and cancer progression. Semin Cell Dev Biol 22: 681-687, 2011

39. Perathoner A, Pirkebner D, Brandacher G, Spizzo G, Stadlmann S, Obrist P, Margreiter R and Amberger A: 14-3-3sigma expression is an independent prognostic parameter for poor survival in colorectal carcinoma patients. Clin Cancer Res 11: 3274-3279, 2005.

40. Wu YJ, Jan YJ, Ko BS, Liang SM and Liou JY: Involvement of 14-3-3 proteins in regulating tumor progression of hepatocellular carcinoma. Cancers (Basel) 7: 1022-1036, 2015.

41. Khongmanee A, Lirdprapamongkol K, Tit-oon P, Chokchaichamnankit D, Svasti J and Srisomsap C: Proteomic analysis reveals important role of 14-3-3 $\sigma$ in anoikis resistance of cholangiocarcinoma cells. Proteomics 13: 3157-3166, 2013.

42. Latham MP, Sekhar A and Kay LE: Understanding the mechanism of proteasome $20 \mathrm{~S}$ core particle gating. Proc Natl Acad Sci USA 111: 5532-5537, 2014

43. Lavabre-Bertrand T, Henry L, Carillo S, Guiraud I, Ouali A, Dutaud D, Aubry L, Rossi JF and Bureau JP: Plasma proteasome level is a potential marker in patients with solid tumors and hemopoietic malignancies. Cancer 92: 2493-2500, 2001.

44. Jakob C,Egerer K, Liebisch P, Türkmen S, Zavrski I, Kuckelkorn U, Heider U, Kaiser M, Fleissner C, Sterz J, et al: Circulating proteasome levels are an independent prognostic factor for survival in multiple myeloma. Blood 109: 2100-2105, 2007. 